\title{
A Comparative Study of the Anion Transfer Kinetics Across a Water/Nitrobenzene Interface by Means of Electrochemical Impedance Spectroscopy and Square-Wave Voltammetry at Thin Organic Film-Modified Electrodes
}

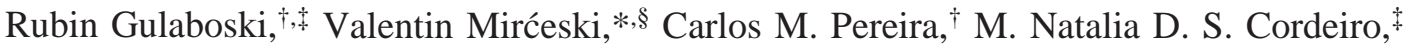 \\ A. Fernando Silva, ${ }^{\dagger}$ François Quentel, ${ }^{\perp}$ Maurice L'Her, ${ }^{\perp}$ and Milivoj Lovrić ${ }^{\#}$ \\ CIQ-UP L4, Faculdade de Ciencias, Universidade do Porto, Rua do Campo Alegre 687, 4169-007 Porto, \\ Portugal, REQUIMTE, Faculdade de Ciencias, Universidade do Porto, Rua do Campo Alegre 687, \\ 4169-007 Porto, Portugal, Institute of Chemistry, Faculty of Natural Sciences and Mathematics, \\ Sv. Kiril i Metodij University, PO Box 162, 1000 Skopje, Republic of Macedonia, Laboratoire de Chimie \\ Analytique, UMR-CNRS 6521, Université de Bretagne Occidentale, 6, avenue Victor Le Gorgeu, \\ C.S. 93837, 29238 BREST Cedex 3, France, and Center for Marine Research Zagreb, \\ Rudjer Bošković Institute, POB 1016, Zagreb 10001, Croatia
}

Received September 21, 2005. In Final Form: December 9, 2005

\begin{abstract}
The kinetics of the transfer of a series of hydrophilic monovalent anions across the water/nitrobenzene (W/NB) interface has been studied by means of thin organic film-modified electrodes in combination with electrochemical impedance spectroscopy and square-wave voltammetry. The studied ions are $\mathrm{Cl}^{-}, \mathrm{Br}^{-}, \mathrm{I}^{-}, \mathrm{ClO}_{4}^{-}, \mathrm{NO}_{3}^{-}, \mathrm{SCN}^{-}$, and $\mathrm{CH}_{3} \mathrm{COO}^{-}$. The electrode assembly comprises a graphite electrode (GE) covered with a thin NB film containing a neutral strongly hydrophobic redox probe (decamethylferrocene or lutetium bis(tetra-tert-butylphthalocyaninato)) and an organic supporting electrolyte. The modified electrode is immersed in an aqueous solution containing a supporting electrolyte and transferring ions, and used in a conventional three-electrode configuration. Upon oxidation of the redox probe, the overall electrochemical process proceeds as an electron-ion charge-transfer reaction coupling the electron transfer at the GE/NB interface and compensates ion transfer across the W/NB interface. The rate of the ion transfer across the W/NB interface is the limiting step in the kinetics of the overall coupled electron-ion transfer reaction. Moreover, the transferring ion that is initially present in the aqueous phase only at a concentration lower than the redox probe, controls the mass transfer regime in the overall reaction. A rate equation describing the kinetics of the ion transfer that is valid for the conditions at thin organic film-modified electrodes is derived. Kinetic data measured with two electrochemical techniques are in very good agreement.
\end{abstract}

\section{Introduction}

The transfer of ions across the interface between two immiscible liquids $(\mathrm{L} / \mathrm{L})$ is a process of particular importance for a variety of areas in chemistry, biology, pharmacy, and metallurgy; hence, it has been intensively studied over the past few decades. ${ }^{1-3}$ Besides studying thermodynamic and mechanistic aspects of the ion transfer, ${ }^{1-3}$ significant efforts have been devoted to develop theories ${ }^{4,5}$ and experimental methods ${ }^{6}$ for measuring the ion transfer kinetics. Most frequently, a four-electrode arrangement has been utilized to study the kinetics of the ion transfer across the interface between two immiscible electrolyte solutions (ITIES) in combination with electrochemical impedance methods, ${ }^{7-17}$

* Corresponding author. E-mail: valentin@iunona.pmf.ukim.edu.mk.

CIQ-UP L4, Universidade do Porto.

$\div$ REQUIMTE, Universidade do Porto.

$\S$ Sv. Kiril i Metodij University.

$\perp$ Université de Bretagne Occidentale.

\# Rudjer Bošković Institute.

(1) Volkov, A. G. Liquid-Liquid Interfaces in Chemical, Biological and Pharmaceutical Applications; Marcel Dekker: New York, 2001; Vol. 95.

(2) Girault, H. H.; Schiffrin, D. J. In Electrochemistry of Liquid-Liquid Interfaces; Bard, A. J., Ed.; Electroanalytical Chemistry, A Series of Advances; Marcel Dekker: New York, 1989; Vol. 15.

(3) Testa, B.; van de Waterbeemd, H.; Folkers, G.; Gay, R. Pharmacokinetic Optimization in Drug Research; Wiley-WCH: Weinheim, Germany, 2001.

(4) Marcus, R. A. J. Chem. Phys. 2000, 113, 1618-1629.

(5) Samec, Z. Electrochim. Acta 1998, 44, 85-90.

(6) Samec, Z. In Liquid-Liquid Interfaces. Theory and Methods; Volkov, A. G., Deamer, D. W., Eds.; CRC Press: Boca Raton, FL, 1996; pp 155-178.

(7) Samec, Z.; Langmaier, J.; Trojanek, A.; Samcova, E.; Malek, J. Anal. Sci. 1998, 14, 35-41. which are among the most powerful electrochemical techniques for kinetic measurements. ${ }^{18,19}$ Because of the rapid ion transfer at the ITIES and the mass transfer limitations, steady-state voltammetry at micro- and nano-sized ITIES has been developed..$^{20-23}$ Manzanares et al. ${ }^{24}$ and Murtomäki et al. ${ }^{25}$ developed methodology to study the ion transfer across a thin

(8) Wandlowski, T.; Marecek, V.; Holub, K.; Samec, Z. J. Phys. Chem. 1989, 93, 8204-8212.

(9) Dvorak, O.; Marecek, V.; Samec, Z. J. Electroanal. Chem. 1990, 284, 205-215.

(10) Wandlowski, T.; Marecek, V.; Samec, Z. J. Electroanal. Chem. 1988, $242,291-302$.

(11) Kakiuchi, T.; Noguchi, J.; Senda, M. J. Electroanal. Chem. 1992, 327, $63-71$.

(12) Koryta, J.; Vanysek, P.; Brezina, M. J. Electroanal. Chem. 1977, 75, 211-228.

(13) Samec, Z.; Langmaier, J.; Trojanek, A. J. Electroanal. Chem. 1999, 463, $232-241$.

(14) Quinn, B.; Lahtinen, R.; Kontturi, K. J. Electroanal. Chem. 1997, 436, 285-290.

(15) Beattie, P. D.; Delay, A.; Girault, H. H. Electrochim. Acta 1995, 39, $2961-2969$

(16) Buck, R. P.; Bronner, W. E. J. Electroanal. Chem. 1986, 197, 179-181. (17) Buck, R. P.; Mãdãraş, M. B.; Mäckel, R. J. Electroanal. Chem. 1994, 366, $55-68$.

(18) Slyters-Rehbach, M.; Sluyters, J. In Electroanalytical Chemistry, A Series of Advances; Bard, A. J., Ed.; Dekker: New York, 1970; Vol. 4, p 1.

(19) Bard, A. J.; Faulkner, L. R., Electrochemical Methods. Fundamental and Applications; Wiley-Interscience: New York, 2000.

(20) Liu, B.; Mirkin, M. V. Electroanalysis 2000, 12, 1433-1446.

(21) Dongping, Z.; Yi, Y.; Yanjing, X.; Bingliang, W.; Yuanhua, S. Electrochim. Acta 2002, 47, 4477-4483.

(22) Cai, C.; Tong, Y.; Mirkin, M. V. J. Phys. Chem. B 2004, 108, 1787217878.

(23) Yuan, Y.; Wang, L.; Amemiya, S. Anal. Chem. 2004, 76, 5570-5578. 
organic layer supported between two aqueous phases. Nakatani et al. ${ }^{26}$ studied the kinetics of electrochemically induced ferrocenium cation across the single-nitrobenzene-microdroplet/ water interface. Nevertheless, because of thermodynamic limitations, most frequently the kinetics of lipophilic tetraalkylammonium cations have been studied, whereas kinetic data of most common inorganic monovalent ions are yet unknown. Kinetics of the alkali metal cations has been also assessed, ${ }^{8,21}$ however, only in the presence of facilitating agents in the organic phase to lower the energy of the ion transfer.

On the basis of all previous studies, it appears that ion transfer kinetics is considerably sensitive to the experimental conditions of the method used for kinetic measurements. For instance, using the method of a thin organic layer supported between two aqueous phases to measure the kinetics of tetraalkylammonium cations, ${ }^{24,25}$ rate constants on the order of $10^{-4} \mathrm{~cm} \mathrm{~s}^{-1}$ have been estimated. In this methodology, the potential deference at the liquid interface was not externally controlled; rather, the transferring ion was at the same time the potential-determining ion. On the other hand, in methods where a macroscopic or micrometer-sized ITIES was externally polarized, the transfer of the same ions appears significantly faster, having rate constants on the order of $\geq 0.1$ $\mathrm{cm} \mathrm{s}^{-1} .{ }^{22}$ To measure such rapid ion transfer reactions with electrochemical impedance spectroscopy (EIS), very high frequencies of the potential modulation are required, which significantly complicates the kinetic measurements.

In the past few years, the three-phase $\mathrm{e}^{27-30}$ and thin organic film-modified electrodes ${ }^{31-33}$ emerged as simple but powerful tools for studying the charge transfer phenomena across the $\mathrm{L} / \mathrm{L}$ interface. These electrodes couple the electron transfer at the graphite electrode (GE)/organic solvent interface with the ion transfer at the organic solvent/water interface. Using chemically stable and strongly hydrophobic redox probes dissolved in the organic phase, novel methods for studying the transfer of numerous highly hydrophilic ions from water to different solvents have been developed. ${ }^{28}$ Some of the studied ions ${ }^{34}$ as well as the organic solvents used ${ }^{35-37}$ were inaccessible with other electrochemical methods.

Using these electrodes in combination with a fast and sensitive voltammetric technique such as square-wave voltammetry (SWV), ${ }^{38}$ a novel method for measuring the kinetics of the ion transfer has recently been proposed. ${ }^{39,40}$ The thin organic film-

(24) Manzanares, J. A.; Lahtinen, R.; Quinn, B.; Kontturi, K., Schifrin, D. J. Electrochim. Acta 1998, 44, 59-71.

(25) Barker, M. H.; Murtomäki, L.; Kontturi, K. J. Electroanal. Chem. 2001, 497, 61-68.

(26) Terui, N.; Nakatani, K.; Kitamura, N. J. Electroanal. Chem. 2000, 494, $41-46$

(27) Scholz, F.; Komorsky-Lovrić, Š.; Lovrić, M. Electrochem. Commun. 2000, $2,112-118$

(28) Scholz, F.; Schröder, U.; Gulaboski, R. Electrochemistry of Immobilized Particles and Droplets; Springer: Heidelberg, Berlin, 2005.

(29) Schröder, U.; Compton, R. G.; Marken, F.; Bull, S. D.; Davies, S. G.; Gilmour, S. J. Phys. Chem. B 2001, 105, 1344-1350.

(30) Wadhawan, J. D.; Evans, R. G.; Banks, C. E.; Wilkins, S. J.; France, R. R.; Oldham, N. J.; Fairbanks, A. J.; Wood, B.; Dalton, D. J.; Schröder, U.; Compton, R. G. J. Phys. Chem. B 2002, 106, 9619-9632.

(31) Shi, C.; Anson, F. C. J. Phys. Chem. B 1998, 102, 9850-9854.

(32) Chung, T. D.; Anson, F. C. Anal. Chem. 2001, 73, 337-342.

(33) Shi, C.; Anson, F. J. Phys. Chem. B 2001, 105, 8963-8969.

(34) Quentel, F.; Mirćeski, V.; L'Her, M. J. Phys. Chem. B 2005, 109, 12621267.

(35) Gulaboski, R.; Mirćeski, V.; Scholz, F. Electrochem. Commun. 2002, 4 , 277-283.

(36) Scholz, F.; Gulaboski, R.; Mirćeski, V.; Langer, P. Electrochem. Commun. 2002, 4, 659-662.

(37) Bouchard, G.; Galland, A.; Carrupt, P.-A.; Gulaboski, R.; Mirćeski, V.; Scholz, F.; Girault, H. Phys. Chem. Chem. Phys. 2003, 5, 3748-3751.

(38) Lovrić, M. In Electroanalytical Methods, Guide to Experiments and Applications; Scholz, F., Ed.; Springer-Verlag: Heidelberg, Berlin, 2002; pp $111-133$.

(39) Quentel, F.; Mirćeski, V.; L’Her, M. Anal. Chem. 2005, 77, 1939-1949.

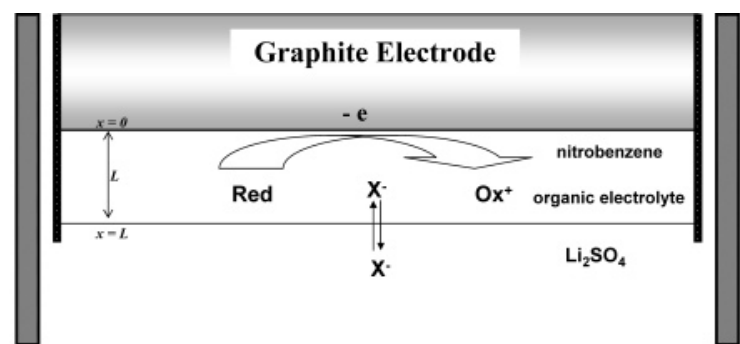

reference electrode

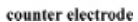

Figure 1. Schematic representation of a thin organic film-modified electrode. The GE is covered with a thin film of NB solution containing a neutral redox probe (Red) and TOATPB as an organic electrolyte. The modified electrode is immersed in $\mathrm{Li}_{2} \mathrm{SO}_{4}$ aqueous electrolyte solution containing transferring ions $\mathrm{X}^{-}$and is used in a conventional three-electrode configuration.

modified electrode used for kinetic measurements consisted of an edge plane pyrolytic graphite (GE) covered with a microfilm of a nitrobenzene (NB) solution containing a neutral, strongly hydrophobic redox probe. ${ }^{39}$ The electrode was immersed in an aqueous electrolyte and used in a conventional three-electrode arrangement. The transferring ion was present in both the organic and aqueous phases in a large excess compared to the redox probe. Thus, the transferring ion was also the potentialdetermining ion at the water (W)/NB interface. When the redox probe was decamethylferrocene (DMFC) or lutetium bis(tetratert-butylphthalocyaninato) $\left(\mathrm{Lu}\left[t \mathrm{Bu}_{4} \mathrm{Pc}_{2}\right)\right.$, and the transferring ions were $\mathrm{ClO}_{4}{ }^{-}, \mathrm{NO}_{3}{ }^{-}$, or $\mathrm{Cl}^{-}$, the kinetics of the overall coupled electron-ion transfer reaction was controlled by the ion transfer across the W/NB interface. ${ }^{39}$

In the present study, the methodology for measuring the ion transfer kinetics using thin organic film-modified electrodes is further developed. To check the capability of this experimental approach, the kinetics of a series of hydrophilic anions has been assessed with two different electrochemical techniques, that is, EIS and SWV. The studied ions were $\mathrm{Cl}^{-}, \mathrm{Br}^{-}, \mathrm{I}^{-}, \mathrm{ClO}_{4}{ }^{-}, \mathrm{NO}_{3}{ }^{-}$, $\mathrm{SCN}^{-}$, and $\mathrm{CH}_{3} \mathrm{COO}^{-}$. To inspect more rigorously whether the ion transfer kinetics is independent of the redox probe, experiments with EIS and SWV have been carried out using different redox probes, that is, DMFC for EIS and $\mathrm{Lu}\left[t \mathrm{Bu}_{4} \mathrm{Pc}\right]_{2}$ for $\mathrm{SWV}$. Moreover, different electrode materials have been used; measurements with EIS and SWV were carried out utilizing black graphite and an edge plane pyrolytic GE, respectively. The variety of all these conditions is the bases for the rigorous assessment of the proposed experimental methodology for measuring the ion transfer kinetics across the $\mathrm{L} / \mathrm{L}$ interface.

All experiments were carried out in the presence of supporting electrolytes in both liquid phases, whereas the transferring ion was initially present only in the aqueous phase at a concentration at least 1 order of magnitude lower than the redox probe (Figure 1). This is a more general approach compared to previous results ${ }^{39,40}$ since no particular electrolyte that is soluble in the organic phase and contains the transferring ion is required. Under selected experimental conditions, the transferring ion controls both the kinetics as well as the mass transfer regime in the overall process. The theoretical model presented considers the mass transfer regime of all electroactive species; hence, it is valid for any concentration ratio of the redox probe and the transferring ion. Moreover, in contrast to the previous study where the kinetics of the ion transfer was described on the basis of a second-order kinetic equation, ${ }^{39}$ the kinetics of the coupled electron-ion transfer reaction at the thin organic film-modified electrode is

(40) Mirćeski, V.; Quentel, F.; L’Her, M.; Pondaven, A. Electrochem. Commun 2005, 7, 1122-1128 
assimilated to a common first-order charge-transfer process, enabling estimation of the ion-transfer rate constants in units of centimeters per second.

\section{Experimental Section}

2.1. Electrochemical Impedance Spectroscopy. All chemicals used were of analytical grade purity. DMFC was purchased from Fluka, while all other chemicals were products of Merck. A watersaturated NB solution containing $0.01 \mathrm{~mol} / \mathrm{L} \mathrm{DMFC} \mathrm{and} 0.05 \mathrm{~mol} / \mathrm{L}$ tetraoctylammonium tetraphenylborate (TOATPB) was used. A graphite rod (black graphite, GrafTech, UCAR SNC, La Lechere, France) was used as a working electrode. $\mathrm{An} \mathrm{Ag} / \mathrm{AgCl}$ (saturated $\mathrm{KCl}$ ) electrode was the reference, while a Pt wire served as a counter electrode. Before modification of the electrode with NB solution, the graphite was abraded with $\mathrm{SiC}$ paper. Thereafter, a $0.1 \mu \mathrm{L} \mathrm{NB}$ solution was imposed on the electrode surface, and the film was formed by spontaneous spreading. The thin-film-modified electrode was submerged into the aqueous solution, containing $0.1 \mathrm{~mol} / \mathrm{L}$ $\mathrm{Li}_{2} \mathrm{SO}_{4}$ as a supporting electrolyte and $5 \mathrm{mmol} / \mathrm{L}$ lithium salt of the transferring anion, that is, $\mathrm{Br}^{-}, \mathrm{I}^{-}, \mathrm{ClO}_{4}^{-}, \mathrm{NO}_{3}^{-}, \mathrm{SCN}^{-}$, and $\mathrm{CH}_{3} \mathrm{COO}^{-} ; \mathrm{Cl}^{-}$was avoided because of its strong chemical affinity toward $\mathrm{DMFC}^{+}$.

Impedance spectra were measured using an FRA Solartron model 1250 , Solartron Instruments, UK. The frequency of the sinusoidal potential varied from $0.5 \mathrm{~Hz}$ to $10 \mathrm{kHz}$, with an amplitude of $20 \mathrm{mV}$. Prior to applying the sinusoidal potential modulation, the electrode was equilibrated for $180 \mathrm{~s}$. The measured and simulated impedance spectra were analyzed with the help of EQUIVCRT software. The stability of the system was checked by performing consecutive cyclic voltammetry prior to and after the impedance measurements. The surface area of the GE was $0.01 \mathrm{~cm}^{2}$. It was assumed that the W/NB interface of the thin-film electrode had the same surface area as the GE. With this value, the charge-transfer resistance was estimated for all studied anions.

2.2. Square-Wave Voltammetry. In these experiments, $\mathrm{Lu}\left[t \mathrm{Bu}_{4}-\right.$ $\mathrm{Pc}]_{2}$ was used as a redox probe. $\mathrm{Lu}\left[t \mathrm{Bu}_{4} \mathrm{Pc}\right]_{2}$ was synthesized as described elsewhere. ${ }^{41,42}$ All other chemicals were of high purity and used as purchased. The redox compound was dissolved in watersaturated NB ( $2 \mathrm{mmol} / \mathrm{L})$. Besides the redox compound, the NB contained $0.1 \mathrm{~mol} / \mathrm{L}$ tetraoctylphosphonium tetraphenylborate (TOPTPB) as an organic supporting electrolyte. TOPTPB was prepared by metathesis of tetraoctylphosphonium bromide (Aldrich) and sodium tetraphenylborate (Merck).

A disk electrode $(0.638 \mathrm{~cm}$ diameter $)$ of edge plane pyrolytic graphite was used. The preparation of the electrode and its pretreatment is described elsewhere. ${ }^{39}$ One microliter of the NB solution was deposited on the GE, and the film formed by spontaneous spreading. The thin-film-modified electrode was then immersed into the aqueous solution containing $0.25 \mathrm{~mol} / \mathrm{L} \mathrm{Li}_{2} \mathrm{SO}_{4}$ as a supporting electrolyte and $0.1 \mathrm{mmol} / \mathrm{L}$ of the transferring anion, that is, $\mathrm{Cl}^{-}$, $\mathrm{Br}^{-}, \mathrm{ClO}_{4}^{-}, \mathrm{NO}_{3}{ }^{-}, \mathrm{SCN}^{-}$, and $\mathrm{CH}_{3} \mathrm{COO}^{-}$. The cation was $\mathrm{Na}^{+}$for $\mathrm{Cl}^{-}, \mathrm{I}^{-}, \mathrm{NO}_{3}{ }^{-}$, and $\mathrm{CH}_{3} \mathrm{COO}^{-} ; \mathrm{NH}_{4}{ }^{+}$for $\mathrm{SCN}^{-}$; and $\mathrm{Li}^{+}$for $\mathrm{ClO}_{4}{ }^{-}$ and $\mathrm{Br}^{-}$.

SW voltammograms were recorded using AUTOLAB equipment (Eco-Chemie, Utrecht, Netherlands). A $\mathrm{KCl}$ saturated calomel electrode (SCE) was used as a reference, and a Pt wire was used as an auxiliary electrode.

For both types of experiments, NB-saturated water (Millipore Q) was used for preparing all aqueous solutions. All experiments were performed at room temperature.

\section{Results and Discussion}

Figure 2 shows net SW voltammograms for the oxidation of $\mathrm{Lu}\left[t \mathrm{Bu}_{4} \mathrm{Pc}\right]_{2}$ in a thin NB film deposited on the surface of an edge plane pyrolytic GE measured in contact with an aqueous electrolyte containing various anions. All voltammetric curves

(41) Pondaven, A.; Cozien, Y.; L'Her, M. New J. Chem. 1992, 16, 711-718.

(42) L'Her, M.; Pondaven, A. In Electrochemistry of Phthalocyanines; Kadish, K., Guilard, R., Smith, K., Eds.; The Porphyrin Handbook. Phthalocyanines: Spectroscopic and Electrochemical Characterization; Academic Press: New York, 2003; Vol. 16, pp 117-170.

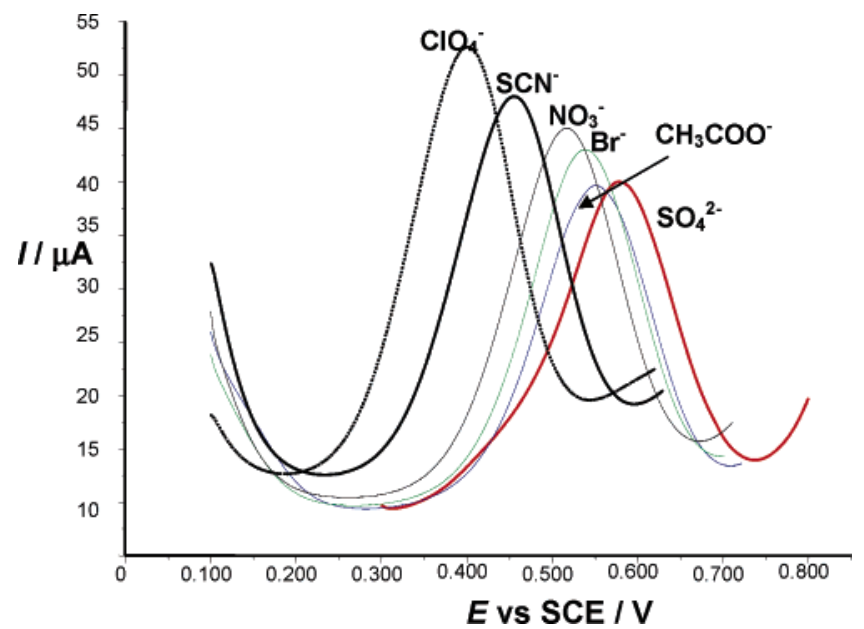

Figure 2. Net $\mathrm{SW}$ voltammograms measured for the oxidation of a $2 \mathrm{mmol} / \mathrm{L} \mathrm{NB}$ solution of $\mathrm{Lu}\left[t \mathrm{Bu}_{4} \mathrm{Pc}_{2}\right.$ deposited as a microfilm at the surface of an edge plane pyrolytic GE accompanied by the transfer of various anions from water to NB. Besides the redox probe, the organic phase contained $0.1 \mathrm{~mol} / \mathrm{L}$ TOPTPB. The aqueous phase contained $0.1 \mathrm{mmol} / \mathrm{L}$ of the corresponding anion and 0.25 $\mathrm{mol} / \mathrm{L} \mathrm{Li}_{2} \mathrm{SO}_{4}$ as a supporting electrolyte. Cations in the aqueous phase were $\mathrm{Na}^{+}$for $\mathrm{Cl}^{-}, \mathrm{I}^{-}, \mathrm{NO}_{3}^{-}$, and $\mathrm{CH}_{3} \mathrm{COO}^{-} ; \mathrm{NH}_{4}{ }^{+}$for $\mathrm{SCN}^{-}$; and $\mathrm{Li}^{+}$for $\mathrm{ClO}_{4}^{-}$and $\mathrm{Br}^{-}$. The voltammogram corresponding to sulfate ions was recorded only in the aqueous supporting electrolyte. The parameters of the potential modulation were frequency $f=8$ $\mathrm{Hz}$; amplitude $E_{\mathrm{sw}}=50 \mathrm{mV}$; and step of the potential modulation $\mathrm{d} E=0.15 \mathrm{mV}$.

were particularly well developed, with stable peak currents $\left(\Delta I_{\mathrm{p}}\right)$ and potentials $\left(E_{\mathrm{p}}\right)$ as well as half-peak widths $\left(\Delta E_{\mathrm{p} / 2}\right)$ for given experimental conditions. Being proportional to the energy of the anion transfer from $\mathrm{W}$ to $\mathrm{NB},{ }^{43}$ the position of the voltammograms depends on the nature of the transferring anion. The peak potentials shift toward more positive potentials when the hydrophilicity of the transferring anions is increased (see Figure 2). Hence, the transfer of the supporting electrolyte ions does not interfere with the transfer of the corresponding anion. Analogous results were obtained using DMFC as a redox probe and black graphite as a working electrode (data not shown). The electrochemical oxidation of both redox compounds at the thin organic filmmodified electrodes can be described by the following general scheme:

$$
\operatorname{Red}_{(\mathrm{NB})}+\mathrm{X}_{(\mathrm{W})}^{-}=\mathrm{Ox}_{(\mathrm{NB})}^{+}+\mathrm{X}_{(\mathrm{NB})}^{-}+\mathrm{e}
$$

The overall process of reaction 1 couples the electron transfer at the GE/NB interface (reaction 2) and the ion transfer at the $\mathrm{NB} / \mathrm{W}$ interface (reaction 3):

$$
\begin{gathered}
\operatorname{Red}_{(\mathrm{NB})}=\mathrm{Ox}_{(\mathrm{NB})}^{+}+\mathrm{e}(\mathrm{GE} / \mathrm{NB}) \\
\mathrm{X}_{(\mathrm{W})}^{-}=\mathrm{X}_{(\mathrm{NB})}^{-}(\mathrm{NB} \mid \mathrm{W})
\end{gathered}
$$

Although the latter two processes occur at separate interfaces, they are simultaneous and cannot be separately identified. If the ion transfer proceeds according to a pure electrochemical mechanism, excluding any chemical interactions between the redox probe and the transferring ion, the ion transfer kinetics is expected to be independent of the chemical nature of the redox probe. Moreover, if the ion transfer is the rate-limiting step, the kinetics of the overall reaction 1 will depend on the nature of the transferring anion. To provide evidence for these assumptions,

(43) Electrochemical Data Base. http://dcwww.epfl.ch/cgi-bin/LE/DB/InterrDB.pl. 


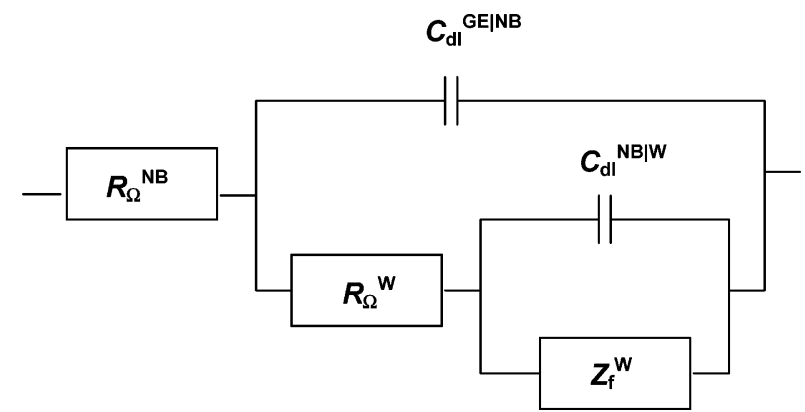

Figure 3. The equivalent circuit describing the electrochemical features of the thin organic film-modified electrode, for the case when the redox probe in the organic phase is in an excess compared to the transferring ion in the aqueous phase, and when the kinetics of the overall process is controlled by the ion transfer across the L/L interface. The element $Z_{\mathrm{f}}$ represents the faradaic impedance in the aqueous phase, which is a series of a charge-transfer resistance $\left(R_{\mathrm{ct}}\right)$ and Warburg impedance $\left(Z_{\mathrm{w}}\right) . R_{\Omega}{ }^{\mathrm{NB}}$ and $R_{\Omega}{ }^{\mathrm{W}}$ denote the ohmic resistance of the NB and the aqueous phase, respectively, whereas $C_{\mathrm{dl}}^{\mathrm{GE} / \mathrm{NB}}$ and $C_{\mathrm{dl}} \mathrm{NB} / \mathrm{w}$ refer to the capacity of the double layers at the $\mathrm{GE} / \mathrm{NB}$ and NB/W interfaces, respectively.

the kinetics of the anion transfers will be studied with two intrinsically diverse electrochemical techniques operating under different experimental conditions.

3.1. Anion Transfer Kinetics Measured by EIS Spectroscopy. The equivalent circuit representing the thin-film-modified electrode immersed in an aqueous electrolyte solution is assumed to be composed of two parallel Randles circuits: one for the organic phase, and the other corresponding to the aqueous phase (Figure 3). Such a circuit, however, can further be simplified due to the following reasons: First, the electron exchange standard rate constant of ferrocene and its derivatives in an organic electrolyte solution is within the interval of $1-10 \mathrm{~cm} \mathrm{~s}^{-1.44}$ thus it is significantly faster than the expected rate of the ion transfers across the liquid interface. ${ }^{4-17}$ Second, in the present experimental arrangement, the bulk concentration of the transferring ion $\left(c_{\mathrm{X}_{(\mathrm{W})}}^{*}\right)$ is at least 1 order of magnitude lower than that of the redox probe $\left(c_{\mathrm{DMFC}}^{*}\right)$. Thus, besides the kinetics, the overall mass transfer regime at the thin organic film-modified electrode is controlled by the transferring ion. Because of these arguments, the faradaic element of the Randles circuit for the organic phase can be omitted since it gives negligible resistance. Therefore, the equivalent circuit representing the thin organic film-modified electrode is simplified to a type that is shown in Figure 3. It is worth noting that this circuit is usually exploited to characterize multilayer coated electrode systems. ${ }^{18,19}$ The faradaic element $\left(Z_{\mathrm{f}}\right)$ in Figure 3 consists of a series of a charge-transfer resistance $\left(R_{\mathrm{ct}}\right)$ and a Warburg impedance element $\left(Z_{\mathrm{w}}\right)$. The charge-transfer resistance is due to the kinetics of the ion transfer across the W/NB interface, while the Warburg impedance element represents the resistance due to the mass transfer of the anions. Note that if the condition $c_{\mathrm{X}_{(\mathrm{W})}}^{*} \ll c_{\mathrm{DMFC}}^{*}$ is not fulfilled in the experiments, the equivalent circuit given in Figure 3 does not provide reliable results.

Shown in Figure 4 are the experimental Nyquist impedance plots for the transfer of several anions, and the corresponding theoretical plots simulated on the basis of the equivalent circuit given in Figure 3. Parameters of the equivalent circuit obtained by fitting to the impedance data are given in Table 1. In all cases, the fitting between the experimental and theoretical data is very good, with an error of less than $5 \%$. This implies that the equivalent circuit is correctly chosen, accurately reflecting the features of

(44) Mirkin, M. V.; Richard, T. C.; Bard, A. J. J. Phys. Chem. 1993, 97, $7672-7677$.
Table 1. Parameters of the Randles-Type Equivalent Circuit of Figure 3 Obtained by a Nonlinear Least-Square Fit to the Impedance Data for Different Anions

\begin{tabular}{lcccccr}
\hline $\begin{array}{l}\text { transferring } \\
\text { ion }\end{array}$ & $\begin{array}{c}C_{\mathrm{dl}} \mathrm{GE} / \mathrm{NB} \\
(\mu \mathrm{F})\end{array}$ & $\begin{array}{c}R_{\Omega}{ }^{\mathrm{NB}} \\
(\mathrm{k} \Omega)\end{array}$ & $\begin{array}{c}C_{\mathrm{dl}}{ }^{\mathrm{NB}} / \mathrm{W} \\
(\mu \mathrm{F})\end{array}$ & $\begin{array}{c}R_{\Omega}{ }^{\mathrm{W}} \\
(\mathrm{k} \Omega)\end{array}$ & $\begin{array}{c}R_{\mathrm{ct}} \\
(\mathrm{k} \Omega)\end{array}$ & $\begin{array}{r}Z_{\mathrm{f}} \mathrm{W} \\
(\mathrm{k} \Omega)\end{array}$ \\
\hline $\mathrm{CH}_{3} \mathrm{COO}^{-}$ & 1.75 & 4.20 & 4.50 & 0.80 & 0.80 & 14.00 \\
$\mathrm{Br}^{-}$ & 5.00 & 2.40 & 7.00 & 1.80 & 0.60 & 16.50 \\
$\mathrm{I}^{-}$ & 10.00 & 3.00 & 26.00 & 0.50 & 0.40 & 3.70 \\
$\mathrm{NO}_{3}{ }^{-}$ & 3.10 & 1.90 & 4.50 & 0.70 & 0.80 & 18.10 \\
$\mathrm{SCN}^{-}$ & 4.10 & 1.90 & 7.30 & 1.20 & 1.55 & 8.85 \\
$\mathrm{ClO}_{4}^{-}$ & 6.40 & 2.50 & 4.10 & 1.55 & 1.60 & 14.70
\end{tabular}

the experimental system. The parameters of the semicircle regions of the Nyquist plots in Figure 4, appearing in the high-frequency regions, mainly reflect the effect of the charge-transfer resistance due to the anion transfer across the W/NB interface (inset of Figure 4B). Furthermore, in the lower frequency region, the major resistance is due to the mass transfer. In this region, a linear relationship between the imaginary $\left(Z^{\prime \prime}\right)$ and the real part $\left(Z^{\prime}\right)$ of the impedances, with a slope of 1 , has been observed for all studied anions (Figure 5). In all cases, the plots of $Z^{\prime}$ or $Z^{\prime \prime}$ versus the square root of the inverse angular frequency $\left(\omega^{-0.5}\right)$ are lines within the low-frequency region, as expected for systems controlled by diffusion mass transfer (data not shown). The last finding can also serve as an indicator that no adsorption phenomena take place at the $\mathrm{W} / \mathrm{NB}$ interface.

For estimating the standard rate constants of anion transfers $\left(k_{\mathrm{s}}\right)$, the charge-transfer resistance $\left(R_{\mathrm{ct}}\right)$ at the equilibrium potential has been evaluated (Table 1). For this purpose, the common relationship between the charge-transfer resistance $R_{\mathrm{ct}}$, and the exchange current $\left(I_{0}\right)$ has been used: $R_{\mathrm{ct}}=R T /\left(F I_{0}\right)$. At equilibrium potential at the thin-film electrode, the exchange current is defined as

$$
I_{0}=F S k_{\mathrm{s}} \exp \left(\beta \varphi_{\mathrm{eq}}\right) c_{\mathrm{X}_{(\mathrm{W})}}^{*}
$$

where $S$ is the surface area of the W/NB interface, and $\beta$ is the transfer coefficient. The relative potential at equilibrium conditions at the thin-film electrode is defined as

$$
\varphi_{\mathrm{eq}}=\frac{F}{R T}\left(E_{\mathrm{eq}}-E_{\mathrm{c}}^{\theta^{\prime}}\right)
$$

$E_{\text {eq }}$ is the equilibrium potential between the GE and the water phase. $E_{\mathrm{c}}{ }^{\theta^{\prime}}$ is the formal potential of the overall reaction 1 , defined as $E_{\mathrm{c}}^{\theta^{\prime}}=E_{\mathrm{Ox} / \text { Red }}^{\theta^{\prime}}+\Delta_{\mathrm{W}}^{\mathrm{NB}} \varphi_{\mathrm{X}}^{\theta}$, where $E_{\mathrm{Ox} / \text { Red }}^{\theta}$ and $\Delta_{\mathrm{W}}^{\mathrm{NB}} \varphi_{\mathrm{X}}^{\theta}$ are the standard potential of the redox couple in the NB solution and the standard potential of the ion transfer from $\mathrm{W}$ to $\mathrm{NB}$, respectively. Furthermore, at equilibrium conditions, the Nernsttype equation holds:

$$
E=E_{\mathrm{Ox} / \mathrm{Red}}^{\theta}+\Delta_{\mathrm{W}}^{\mathrm{NB}} \varphi_{\mathrm{X}}^{\theta}+\frac{R T}{F} \ln \frac{\left(c_{\mathrm{Ox}}\right)_{x=0}\left(c_{\mathrm{X}_{(\mathrm{NB})}}\right)_{x=L}}{\left(c_{\mathrm{Red}}\right)_{x=0}\left(c_{\mathrm{X}_{(\mathrm{W})}}\right)_{x=L}}
$$

where $x=0$ and $x=L$ denote the positions at the GE and the W/NB interface, respectively (Figure 1). As the experiment is performed under the condition $c_{\mathrm{X}_{(\mathrm{W})}}^{*} \ll c_{\mathrm{Red}}^{*}$, the equilibrium potential is defined as

$$
E_{\mathrm{eq}}=E_{\mathrm{Ox} / \mathrm{Red}}^{\theta}+\Delta_{\mathrm{W}}^{\mathrm{NB}} \varphi_{\mathrm{X}}^{\theta}-\frac{R T}{F} \ln \left(c^{*}{ }_{\mathrm{Red}} / c_{\mathrm{s}}\right)
$$

where $c_{\mathrm{s}}=1 \mathrm{~mol} / \mathrm{L}$ is the standard concentration. A combination of eqs 7, 5, and 4 yields the final expression for the exchange current at the thin-film electrodes:

$$
I_{0}=F S k_{\mathrm{s}}\left(c_{\mathrm{Red}}^{*} / \mathrm{c}_{\mathrm{s}}\right)^{-\beta} c_{\mathrm{X}_{(\mathrm{W})}^{*}}
$$



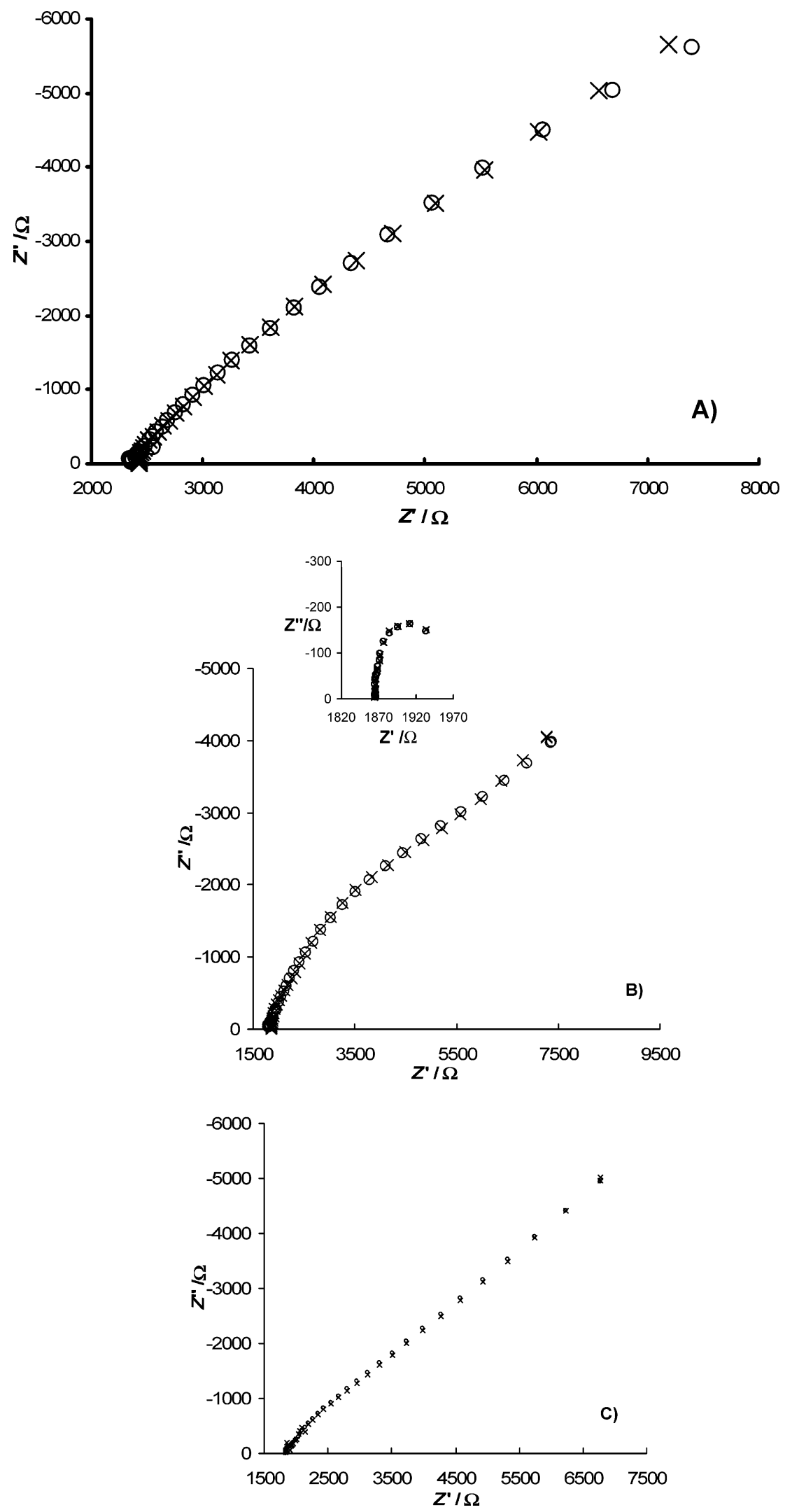

Figure 4. Nyquist impedance plots representing the oxidation of DMFC in the organic film accompanied by the simultaneous transfer of $\mathrm{ClO}_{4}^{-}$(A), $\mathrm{SCN}^{-}$(B), and $\mathrm{NO}_{3}^{-}$(C) from water to NB. The NB solution contained $0.01 \mathrm{~mol} / \mathrm{L}$ DMFC and $0.05 \mathrm{~mol} / \mathrm{L}$ TOATPB, while the aqueous phase contained lithium salt of transferable anions at a concentration of $5 \mathrm{mmol} / \mathrm{L}$, and $0.1 \mathrm{~mol}^{2} \mathrm{~L} \mathrm{Li}_{2} \mathrm{SO}_{4}$ as a supporting electrolyte. The experimental and theoretical data are designated with " $\times$ " and " $O$ ", respectively. The simulations were performed on the basis of the equivalent circuit given in Figure 3. The inset of panel B represents the fitting in the high-frequency region for the transfer of $\mathrm{SCN}^{-}$.

The estimated values of the standard rate constants of ion transfer based on eq 8 are listed in the last column of Table 2.
For this, it has been assumed that $\beta=0.5$. As shown in Table 1 , the charge-transfer resistance is dependent on the nature of 


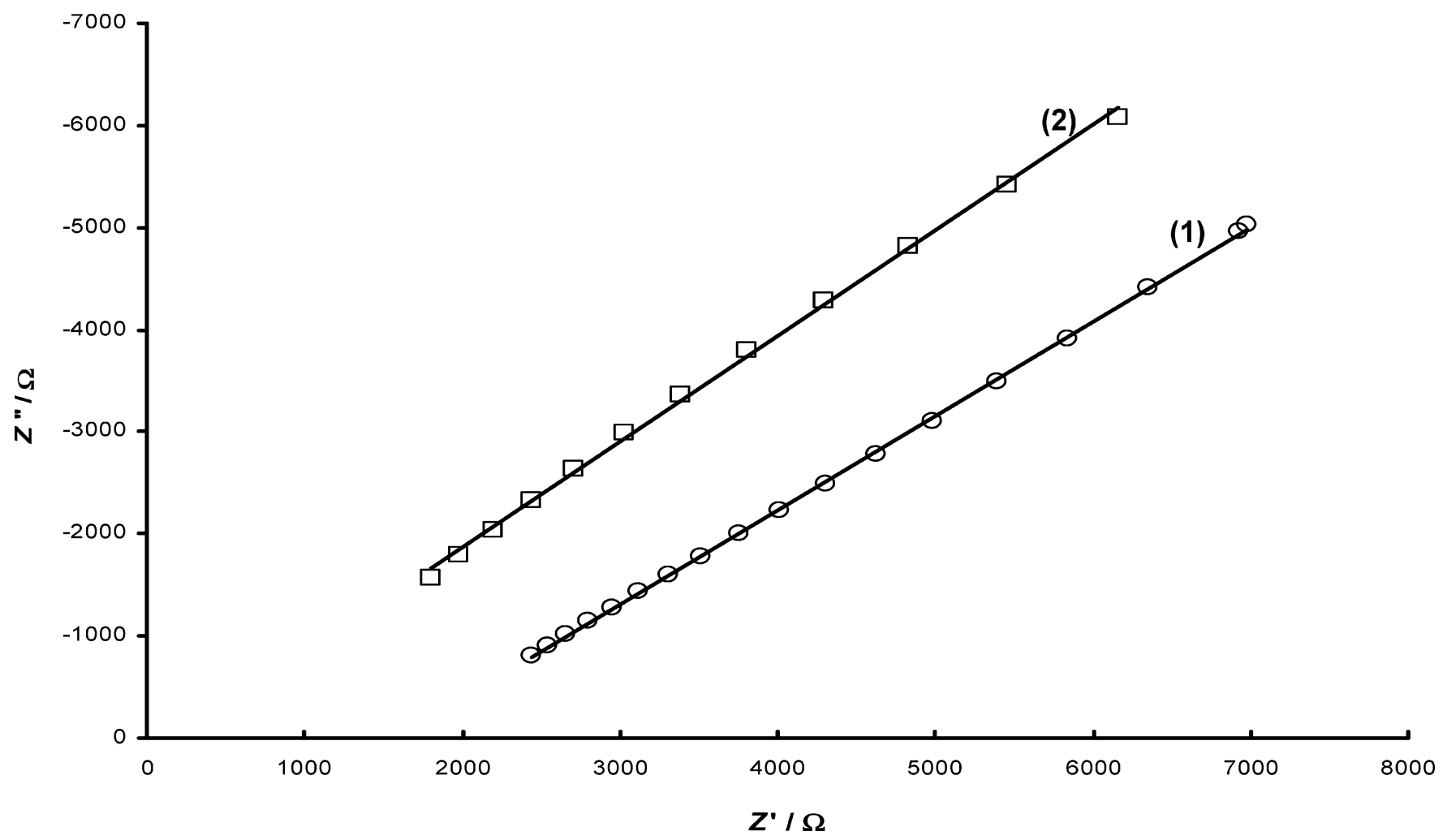

Figure 5. The dependence between the imaginary $\left(Z^{\prime \prime}\right)$ and the real part $\left(Z^{\prime}\right)$ of the impedance for the transfer of $\mathrm{SCN}^{-}(1)$ and $\mathrm{NO}_{3}{ }^{-}(2)$ in a low-frequency region. The experimental conditions are the same as those in Figure 4.

Table 2. Analysis of the Voltammetric Response and the Quasireversible Maximums Measured by the Oxidation of $\mathrm{Lu}\left[t \mathrm{Bu}_{4} \mathrm{Pc}\right]_{2}$ in the Presence of Different Anions in the Aqueous Phase $^{a}$

\begin{tabular}{|c|c|c|c|c|c|}
\hline $\begin{array}{l}\text { transferring } \\
\text { ion }\end{array}$ & $\begin{array}{c}E_{\mathrm{p}} \\
(\mathrm{mV})\end{array}$ & $\begin{array}{l}\Delta E_{\mathrm{p} / 2} \\
(\mathrm{mV})\end{array}$ & $\begin{array}{l}\text { crit. } \\
\text { freq. } \\
f_{\max } \\
(\mathrm{Hz})\end{array}$ & $\begin{array}{c}\text { SWV } \\
k_{\mathrm{s}} \times 10^{2} \\
\left(\mathrm{~cm} \mathrm{~s}^{-1}\right)\end{array}$ & $\begin{array}{c}\text { EIS } \\
k_{\mathrm{s}} \times 10^{2} \\
\left(\mathrm{~cm} \mathrm{~s}^{-1}\right)\end{array}$ \\
\hline $\mathrm{CH}_{3} \mathrm{COO}^{-}$ & $584 \pm 12$ & $142 \pm 10$ & 39 & $2.26 \pm 0.23$ & $3.26 \pm 0.16$ \\
\hline $\mathrm{Cl}^{-}$ & $605 \pm 5$ & $122 \pm 8$ & 70 & $2.99 \pm 0.30$ & \\
\hline $\mathrm{Br}^{-}$ & $541 \pm 13$ & $152 \pm 9$ & 60 & $2.77 \pm 0.28$ & $4.34 \pm 0.22$ \\
\hline $\mathrm{I}^{-}$ & $419 \pm 5$ & $161 \pm 10$ & 80 & $3.57 \pm 0.36$ & $6.52 \pm 0.33$ \\
\hline $\mathrm{NO}_{3}{ }^{-}$ & $508 \pm 8$ & $164 \pm 10$ & 20 & $1.60 \pm 0.16$ & $3.26 \pm 0.16$ \\
\hline $\mathrm{SCN}^{-}$ & $462 \pm 3$ & $131 \pm 8$ & 25 & $1.79 \pm 0.18$ & $1.68 \pm 0.08$ \\
\hline $\mathrm{ClO}_{4}^{-}$ & $397 \pm 8$ & $143 \pm 3$ & 15 & $0.98 \pm 0.10$ & $1.63 \pm 0.08$ \\
\hline
\end{tabular}

${ }^{a}$ The standard rate constants listed in the fifth column were calculated on the basis of eq 14 with $K_{\max }=1.13 \pm 0.11$ and $D=5 \times 10^{-6} \mathrm{~cm}^{2}$ $\mathrm{s}^{-1}$. The other conditions in both experiment and simulations were the same as in Figure 7. The last column shows the standard rate constants estimated by EIS with the aid of eq 8 and the charge-transfer resistances listed in Table 1. The conditions of the EIS measurements were $S=0.01$ $\mathrm{cm}^{2}, T=292 \mathrm{~K}, c_{\mathrm{DMFC}}^{*}=10 \mathrm{mmol} / \mathrm{L}$, and $c_{\mathrm{X}_{(\mathrm{W})}}^{*}=0.1 \mathrm{mmol} / \mathrm{L}$. For both SWV and EIS, it has been assumed that the transfer coefficient is $\beta=$ 0.5 .

the transferring ion, implying that the ion transfer is the ratedetermining step. The charge-transfer resistance has been determined with an error of less than $5 \%$.

3.2. Anion Transfer Kinetics Measured by SWV. For extraction of the kinetic information from SW voltammetric measurements, it is of critical importance to derive kinetic equation that can valuably describe the kinetically controlled coupled electron-ion transfer reaction 1 at the thin organic film-modified electrode. ${ }^{40,45}$ Both charge-transfer processes 2 and 3 are coupled by virtue of the same current. The rate of the overall process,

(45) Komorsky-Lovrić, Š.; Lovrić, M. Cent. Eur. J. Chem. 2005, 3, 216-224. and hence the current flowing through the system, is dictated by the slower step, which, in general, can be either the electron (reaction 2) or the ion transfer (reaction 3). When the ion transfer is the rate-determining step, the following condition at the NB/W interface holds:

$$
\frac{I}{F S}=k_{\mathrm{s}} \exp \left(\beta \varphi_{\mathrm{NB} / \mathrm{W}}\right)\left[\left(c_{\mathrm{X}_{(\mathrm{W})}}\right)_{x=L}-\exp \left(-\varphi_{\mathrm{NB} / \mathrm{W}}\right)\left(c_{\mathrm{X}_{(\mathrm{NB})}}\right)_{x=L}\right]
$$

Here, it is assumed that the Butler-Volmer formalism holds for the ion transfer kinetics, where $\beta$ is the transfer coefficient, and $k_{\mathrm{s}}$ is a phenomenological standard rate constant of ion transfer in units of centimeters per second. For the meanings of all other symbols and abbreviations, see Table 3 . Note that the ion transfer is driven by the relative potential difference at the NB/W interface defined as $\varphi_{\mathrm{NB} / \mathrm{W}}=F / R T\left(\Delta_{\mathrm{W}}^{\mathrm{NB}} \varphi-\Delta_{\mathrm{W}}^{\mathrm{NB}} \varphi_{\mathrm{X}}^{\theta}\right)$, where $\Delta_{\mathrm{W}}^{\mathrm{NB}} \varphi$ is the Galvani potential difference between NB and $\mathrm{W}$, and $\Delta_{\mathrm{W}}^{\mathrm{NB}} \varphi_{\mathrm{X}}^{\theta}$ is the standard potential of the anion transfer from $\mathrm{W}$ to NB. $\left(c_{\mathrm{X}_{(\mathrm{W})}}\right)_{x=L}$ and $\left(c_{\mathrm{X}_{(\mathrm{NB})}}\right)_{x=L}$ are surface concentrations of the transferring ion at the $\mathrm{L} / \mathrm{L}$ interface, which is positioned at a distance $x=L$ from the electrode surface. The relative potential difference at the NB/W interface is related with the relative potential difference at the GE/NB interface through the following relation:

$$
\varphi_{\mathrm{GE} / \mathrm{NB}}+\varphi_{\mathrm{NB} / \mathrm{W}}=\varphi_{\mathrm{GE} / \mathrm{W}}
$$

Here, $\varphi_{\mathrm{GE} / \mathrm{W}}$ is the relative potential difference between the $\mathrm{GE}$ and the water phase defined as $\varphi_{\mathrm{GE} / \mathrm{W}}=F / R T\left(E_{\mathrm{GE} / \mathrm{W}}-E_{\mathrm{c}}^{\theta^{\prime}}\right)$, where $E_{\mathrm{GE} / \mathrm{W}}$ is the potential between the working electrode and the water phase that is potentiostatically controlled during the voltammetric experiment. Recall that $E_{\mathrm{c}}^{\theta^{\prime}}$ is the formal potential of the overall reaction 1 , defined as $E_{\mathrm{c}}^{\theta^{\prime}}=E_{\text {Ox } / \operatorname{Red}}^{\theta}+\Delta_{\mathrm{W}}^{\mathrm{NB}} \varphi_{\mathrm{X}}^{\theta} \cdot{ }^{27}$ The conversion rate of the redox couple at the GE/NB interface 
Table 3. List of Symbols and Abbreviations

\begin{tabular}{|c|c|c|}
\hline symbol & meanings of the symbols and abbreviations & units \\
\hline$b$ & ion transfer coefficient & 1 \\
\hline$C$ & capacity & $\mathrm{F}$ \\
\hline$c_{\mathrm{Ox}}$ & concentration of the oxidized form & $\mathrm{mol} \mathrm{cm} \mathrm{cm}^{-3}$ \\
\hline$c_{\text {Red }}$ & concentration of the reduced form & $\mathrm{mol} \mathrm{cm}^{-3}$ \\
\hline$c_{\mathrm{Red}}^{*}$ & bulk concentration of the reduced form & $\mathrm{mol} \mathrm{cm}^{-3}$ \\
\hline$c_{\mathrm{X}_{(\mathrm{W})}}$ & concentration of the transferring ion in the aqueous phase & $\mathrm{mol} \mathrm{cm}-3$ \\
\hline$c_{\mathrm{X}_{\mathrm{NB}}}$ & concentration of the transferring ion in the NB solution & $\mathrm{mol} \mathrm{cm}^{-3}$ \\
\hline$c_{\mathrm{X}^{*}}^{*}$ & bulk concentration of the transferring ion in the aqueous phase & $\mathrm{mol} \mathrm{cm} \mathrm{cm}^{-3}$ \\
\hline$D^{(\mathrm{W})}$ & diffusion coefficient & $\mathrm{cm}^{2} \mathrm{~s}^{-1}$ \\
\hline$\Delta_{\mathrm{W}}^{\mathrm{NB}} \varphi_{\mathrm{X}}^{\theta}$ & standard potential of ion transfer from water to NB & $\mathrm{V}$ \\
\hline & scan increment & $\mathrm{mV}$ \\
\hline$E$ & potential & \\
\hline$E_{\mathrm{sw}}$ & amplitude of the potential modulation & $\mathrm{mV}$ \\
\hline$E_{\text {Ox/Red }}^{\theta}$ & standard redox potential & $\mathrm{V}$ \\
\hline$f^{\text {Ox/Red }}$ & SW frequency & $\mathrm{s}^{-1}$ \\
\hline$Z$ & impedance & W \\
\hline$f_{\max }$ & frequency associated with the position of the quasireversible maximum & $\mathrm{s}^{-1}$ \\
\hline$F$ & Faraday constant & $\mathrm{C} / \mathrm{mol}$ \\
\hline $\mathrm{j}$ & dimensionless potential & 1 \\
\hline$I_{0}$ & exchange current & A \\
\hline I & current & A \\
\hline$\Delta I_{\mathrm{p}}$ & real net peak current & A \\
\hline$K$ & dimensionless kinetic parameter & 1 \\
\hline$k_{\mathrm{s}}$ & standard rate constant & $\mathrm{cm} \mathrm{s}^{-1}$ \\
\hline$L$ & thickness of the film & $\mathrm{cm}$ \\
\hline$R_{\Omega}$ & resistance & W \\
\hline$R$ & gas constant & $\mathrm{J} \mathrm{mol}^{-1} \mathrm{~K}^{-1}$ \\
\hline$r$ & concentration ratio & 1 \\
\hline$S$ & electrode surface area & $\mathrm{cm}^{2}$ \\
\hline$T$ & thermodynamic temperature & $\mathrm{K}$ \\
\hline$x$ & distance & $\mathrm{cm}$ \\
\hline$\Delta \Psi_{\mathrm{p}}$ & dimensionless net peak current & 1 \\
\hline
\end{tabular}

$(x=0)$ is controlled by the current, hence

$$
D\left(\frac{\partial c_{\text {Red }}}{\partial x}\right)_{x=0}=-D\left(\frac{\partial c_{\mathrm{Ox}}}{\partial x}\right)_{x=0}=\frac{I}{F S}
$$

The physical meaning of eqs 9 and 11 is that the rate of both charge-transfer processes 2 and 3 , proceeding at separate interfaces, is identical. However, the surface concentrations of the Red and Ox forms are related to the relative potential difference at the GE/NB interface as follows:

$$
\left(c_{\mathrm{Ox}}\right)_{x=0}=\left(c_{\mathrm{Red}}\right)_{x=0} \exp \left(\varphi_{\mathrm{GE} / \mathrm{NB}}\right)
$$

A combination of eqs 9,10 , and 12 yields

$$
\begin{aligned}
& \frac{I}{F S}=k_{\mathrm{s}} \exp \left(\beta \varphi_{\mathrm{GE} / \mathrm{W}}\right)\left[\frac{\left(c_{\mathrm{Ox}}\right)_{x=0}}{\left(c_{\mathrm{Red}}\right)_{x=0}}\right]^{-\beta} \times \\
& \left\{\left(c_{\mathrm{X}_{(\mathrm{W})}}\right)_{x=L}-\exp \left(-\varphi_{\mathrm{GE} / \mathrm{W}}\right)\left[\frac{\left(c_{\mathrm{Ox}}\right)_{x=0}}{\left(c_{\mathrm{Red}}\right)_{x=0}}\right]\left(c_{\mathrm{X}_{(\mathrm{NB})}}\right)_{x=L}\right\}
\end{aligned}
$$

The latter equation is a basis for the simulation of the kinetically controlled coupled electron-ion transfer reaction 1 at the thinfilm-modified electrode, when ion transfer is the rate-limiting step. For derivation of a numerical solution based on eq 13, the concentrations of both forms of the redox couple at the electrode surface, as well as the concentrations of the transferring ion at the $\mathrm{L} / \mathrm{L}$ interface, are required. The diffusion of the transferring ion in the aqueous phase proceeds under semi-infinite conditions. Thus, the solution of the surface concentration of the ion at the L/L interface, $\left(c_{\mathrm{X}_{(\mathrm{W})}}\right)_{x=L}$, is well-known. ${ }^{38}$ The diffusion of both forms of the redox couple, as well as that of the transferring ion in the organic phase, occurs within the limited boundaries of the thin film. The mathematical solutions for these species can be

derived according to the procedure derived previously. ${ }^{46}$ The final numerical solution of eq 13 was derived according to the modified step-function method. ${ }^{47}$

Numerical solution revealed that the apparent reversibility of the overall reaction depends on the dimensionless kinetic parameter $K=k_{\mathrm{s}}(D f)^{-1 / 2}$ and the concentration ratio $\rho=\left(c_{\mathrm{X}_{(\mathrm{W})}}^{*}\right) /$ $\left(c_{\mathrm{Red}}^{*}\right)$, where $c_{\mathrm{X}_{(\mathrm{W})}}^{*}$ and $c_{\mathrm{Red}}^{*}$ are the bulk concentrations of the transferring ion and the redox probe, respectively. Over the interval of $-2 \leq \log (K) \leq 1$, reaction 1 appears quasireversible. As shown in Figure 6, within the quasireversible region, the dimensionless net $\mathrm{SW}$ peak current $\left(\Delta \Psi_{\mathrm{p}}\right)$ depends parabolically on $\log (K)$, reaching a maximum for a certain critical value of the kinetic parameter $\left(K_{\max }\right)$. Note that the dimensionless net SW peak current is defined as $\Delta \Psi_{\mathrm{p}}=\Delta I_{\mathrm{p}} /\left(F S c_{\text {Red }}^{*} \sqrt{D f}\right)$, where $\Delta I_{\mathrm{p}}$ is the real net peak current, $f$ is the frequency of the potential modulation, and the other symbols have their usual meaning. The parabolic dependence of the dimensionless net SW peak current on the kinetic parameter is the most intriguing property of the overall reaction at the thin organic film-modified electrode known as a "quasireversible maximum". The origin and the behavior of the quasireversible maximum are elaborated on in detail elsewhere. ${ }^{39,48}$ The importance of the quasireversible maximum stems from the fact that it can be exploited for estimation of the standard rate constant in a simple procedure. ${ }^{39,40,48}$

Additionally, Figure 6 shows theoretical quasireversible maximums simulated for various thickness of the film. Obviously, the position of the maximum, and hence the critical kinetic parameter $K_{\max }$, is virtually independent of the film thickness. This is of particular importance since $K_{\max }$ is used for estimation of the standard rate constant. On the other hand, the film thickness

(46) Mirćeski, V. J. Phys. Chem. B 2004, 108, 13719-13725.

(47) Mirćeski, V. J. Electroanal. Chem. 2003, 545, 29-37.

(48) Komorsky-Lovrić, Š.; Lovrić, M. Anal. Chim. Acta 1995, 305, 248-255. 


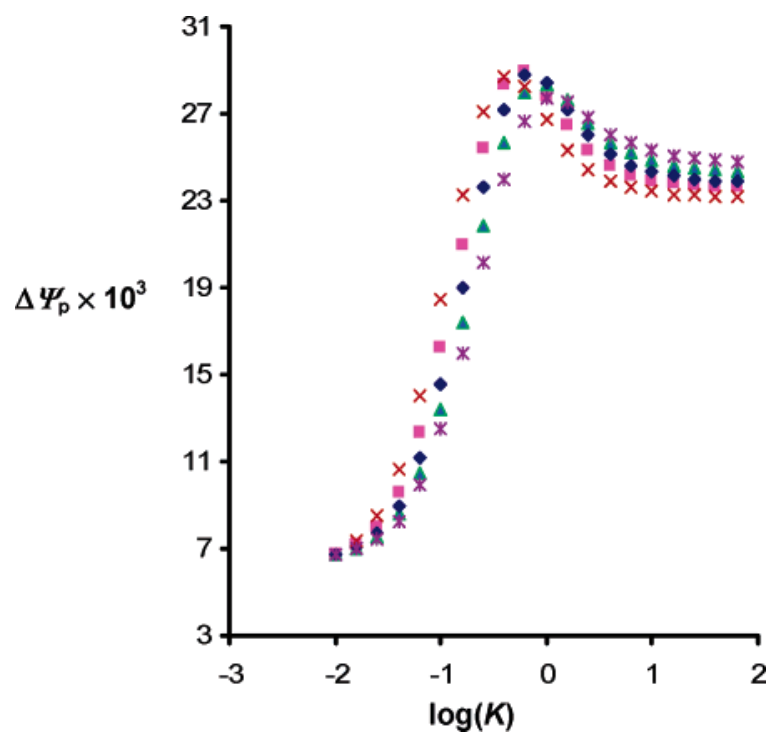

Figure 6. Theoretical quasireversible maximums simulated for the film thickness varying from 2 to $6 \mu \mathrm{m}$. The other conditions of the simulations were $c_{\mathrm{X}_{(\mathrm{W})}}^{*}=0.1 \mathrm{mmol} / \mathrm{L}, c_{\mathrm{Red}}^{*}=4 \mathrm{mmol} / \mathrm{L}, \beta=0.5$, $f=10 \mathrm{~Hz}, D=1 \times 10^{-5} \mathrm{~cm}^{2} \mathrm{~s}^{-1}$, amplitude $E_{\mathrm{sW}}=50 \mathrm{mV}$, and potential step $\mathrm{d} E=10 \mathrm{mV}$.

is not known accurately in the experimental analysis. ${ }^{39}$ Under selected experimental conditions, that is, $c_{\mathrm{X}_{(\mathrm{W})}^{*}}^{*} \ll c_{\mathrm{Red}}^{*}$, the overall mass transfer regime is predominantly controlled by the semiinfinite diffusion of the transferring ion, and the effect of the film thickness on the dimensionless response is insignificant. For these reasons the critical kinetic parameter $K_{\max }$, associated with the position of the quasireversible maximum, is almost independent of the film thickness, as depicted in Figure 6.

In the experimental analysis, one inspects the variation of the ratio $\Delta I_{\mathrm{p}} f^{-1 / 2}$ with the frequency of the potential modulation. Note that this ratio corresponds to the dimensionless net SW peak current. The ratio $\Delta I_{\mathrm{p}} f^{-1 / 2}$ reaches a maximum for a certain critical frequency $\left(f_{\max }\right)$ that satisfies the criterion $k_{\mathrm{s}}\left(D f_{\max }\right)^{-1 / 2}$ $=K_{\max }$. Therefore, different reactions will be associated with different positions of the quasireversible maximum, provided their standard rate constants are not identical. Therefore, calculating the critical kinetic parameter on the basis of numerical simulations and experimentally measuring the critical frequency, the standard rate constant can be estimated through the simple relation

$$
k_{\mathrm{s}}=K_{\max } \sqrt{D f_{\max }}
$$

Figure 7 shows a few experimental quasireversible maximums for different anions, while the complete analysis of all quasireversible maximums is presented in Table 2 . The quasireversible maximums observed for different transferring anions clearly confirm that the anion rate transfer is the determining step. In the analysis of the quasireversible maximums, besides the net SW peak current, both peak potentials and half-peak widths were carefully inspected. As shown in Table 2, the variation of these parameters does not exceed $\pm 10 \mathrm{mV}$ for all anions. These results satisfy the criteria to distinguish between the effects of the chargetransfer kinetics and the uncompensated resistance, ${ }^{49}$ which is of critical importance for accurate estimation of the kinetic parameters. The standard rate constants for the anion transfer have been estimated on the basis of eq 14 using the value of $K_{\max }$ $=1.13 \pm 0.11$, determined by numerical simulations. Note that,

(49) Mirčeski, V.; Gulaboski, R.; Scholz, F. J. Electroanal. Chem. 2004, 566, $351-360$.

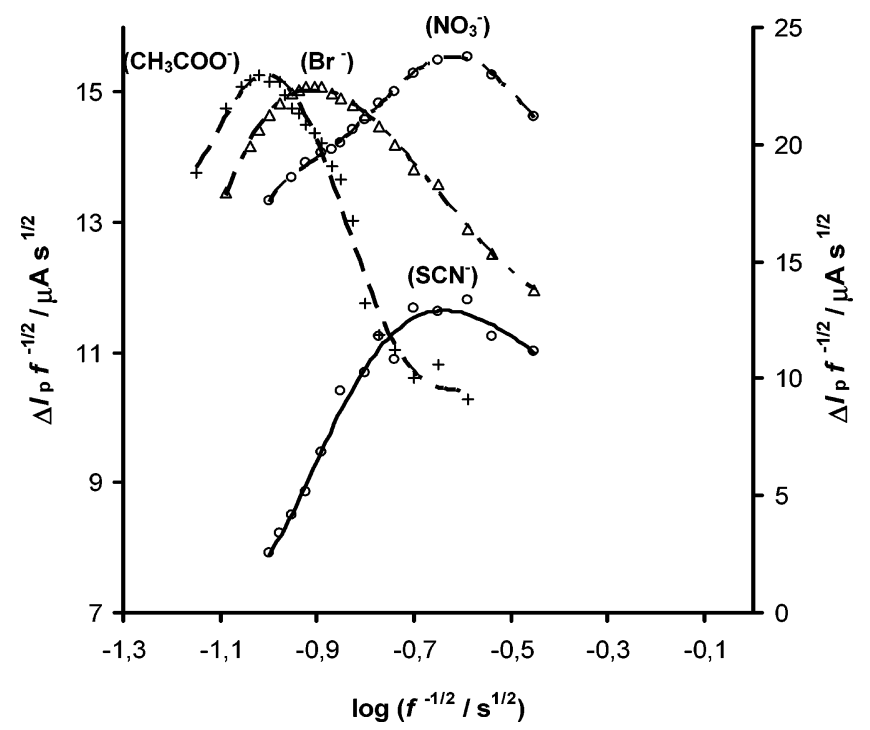

Figure 7. Quasireversible maximums measured by the oxidation of an NB solution of $\mathrm{Lu}\left[t \mathrm{Bu}_{4} \mathrm{Pc}\right]_{2}$ deposited as a microfilm at the surface of an edge plane pyrolytic GE, corresponding to the transfer of anions indicated on the graph. The data for $\mathrm{CH}_{3} \mathrm{COO}^{-}$and $\mathrm{Br}^{-}$ corresponds to the right ordinate. All other conditions are the same as those in Figure 2.

in the numerical simulations, the quasireversible maximum has been constructed by varying the frequency of the potential modulation. In this approach, the simulations and the experimental analysis were performed in the same way. In the simulations, it was assumed that $D=5 \times 10^{-6} \mathrm{~cm}^{2} \mathrm{~s}^{-1}$ and $\beta=0.5$, whereas the other conditions were the same as those in the experiment (Figure 7). The estimated values for the standard rate constants for the transfer of studied ions across the W/NB interface are listed in Table 2. The estimates are with a precision of $\pm 10 \%$.

The correlation between the kinetic data measured with EIS and that measured with SWV is associated with the following linear regression line: $y=1.8398 x-0.0053(R=0.925)$. The intercept of the regression line is close to the idealized value 0 , indicating a good agreement between the kinetic parameters estimated by EIS and SWV.

Rigorously speaking, the kinetic data measured with two electrochemical methods under corresponding experimental conditions should be identical. The differences in the rate constants listed in Table 2 could originate from various sources. For instance, in EIS, the true exchange current measured at equilibrium conditions at the W/NB interface could be slightly affected by the partition concentration of the transferring ion, for example, $\mathrm{ClO}_{4}{ }^{-}$. Moreover, during EIS measurements at high frequencies, it is likely to assume the impact of a resistance originating from sources other than the ion transfer reaction. This uncompensated resistance could also slightly affect the SW voltammetric measurements, although care was taken to recognize and avoid this effect. ${ }^{49}$ In addition, in SWV, one should be aware of the discrepancy in the current sampling procedure used in a real experiment and simulations. In the latter case, a single potential pulse is divided into 25 time increments, and the current is measured in the last point, whereas, in the real experiment, the current is measured at several points within a time interval at the end of the potential pulse, and then an integrated value is reported. ${ }^{38}$

\section{Conclusion}

The current study confirmed that thin organic film-modified electrodes are simple and valuable experimental tools for the measurement of ion kinetics transfer across the $\mathrm{L} / \mathrm{L}$ interface. 
These electrodes, in combination with hydrophobic redox compounds such as DMGC or $\mathrm{Lu}\left[t \mathrm{Bu}_{4} \mathrm{Pc}\right]_{2}$, enable assessment of the kinetics of strongly hydrophilic ions that are not accessible with other electrochemical methods. Both EIS and SWV provide consistent kinetic data and confirm that ion transfer is the ratedetermining step in the overall coupled electron-ion transfer reaction.

The estimated rate constants are all close to $0.01 \mathrm{~cm} \mathrm{~s}^{-1}$. In agreement with other methods, different ions are characterized with similar rate constants. Although kinetic data for the transfers of $\mathrm{Cl}^{-}, \mathrm{Br}^{-}, \mathrm{I}^{-}, \mathrm{NO}_{3}{ }^{-}$, and $\mathrm{CH}_{3} \mathrm{COO}^{-}$across the W/NB interface are lacking in the literature, in general, the rate constants estimated with the current method are slightly lower than those estimated from voltammetry at a four-electrode arrangement.

The principle difference in the experimental methodologies based on thin-film electrodes and those based on a four-electrode arrangement at the ITIES is in the mechanism of polarization of the $\mathrm{L} / \mathrm{L}$ interface. In the thin-film voltammetric experiment, the liquid interface cannot be electrically polarized by the help of potentiostat. The polarization of the liquid interface that drives the ion transfer reaction is a consequence of the electrode reaction at the electrode/organic solvent interface. In the four-electrode experiment, the ITIES is electrically polarized by the help of two reference electrodes. Hence, the electric properties of the liquid interface in these two experimental arrangements are expected to be different, which might be a reason for the slight differences in the ion-transfer rate constants.

Acknowledgment. R.G. thanks the Fundação para a Ciência e a Tecnologia (FCT) of Portugal for providing of a postdoctoral fellowship (SFRH/BPD/14894/2004). V.M. gratefully acknowledges the financial support of the Alexander von HumboldtStiftung Foundation. C.M.P., M.N.D.S.C., and A.F.S. would like to thank the FCT for financial support (CIQ L4 and FEDER for the project POCTI/QUI/42472/2001).

LA052565K 